\title{
Toll-Like Receptors 2 and 4 Cooperate in the Control of the Emerging Pathogen Brucella microti
}

\author{
Maykel A. Arias ${ }^{1}$, Llipsy Santiago ${ }^{1}$, Santiago Costas-Ramon ${ }^{1}$, Paula Jaime-Sánchez ${ }^{1}$, \\ Marina Freudenberg ${ }^{2 t}$, Maria P. Jiménez De Bagüés ${ }^{3 * \neq}$ and Julián Pardo ${ }^{1,4,5 * \neq}$ \\ ${ }^{1}$ Cell Immunity in Cancer, Inflammation and Infection Group, Department of Biochemistry and Molecular and Cell Biology, \\ Biomedical Research Centre of Aragon (CIBA), IIS Aragon, University of Zaragoza, Zaragoza, Spain, ${ }^{2}$ Max-Planck Institute for \\ Immunobiology and Epigenetics, Freiburg, Germany, ${ }^{3}$ Unidad de Producción y Sanidad Animal, Centro de Investigación y \\ Tecnología Agroalimentaria, Instituto Agroalimentario de Aragón - IA2, CITA-Universidad de Zaragoza, Zaragoza, Spain, \\ ${ }^{4}$ Nanoscience Institute of Aragon, University of Zaragoza, Zaragoza, Spain, ${ }^{5}$ Aragon I+D Foundation, Zaragoza, Spain
}

\section{OPEN ACCESS}

Edited by:

Philip R. Hardwidge,

Kansas State University, USA

Reviewed by:

Jeff Shannon,

National Institute of Allergy and Infectious Diseases (NIH), USA

Christian Rueter,

Universitätsklinikum Münster,

Germany

*Correspondence:

Maria P. Jiménez De Bagüés mpjimenezdebagues@aragon.es Julián Pardo

pardojim@unizar.es

${ }^{\dagger}$ Present Address:

Marina Freudenberg,

BIOSS Centre for Biological Signalling Studies, Albert-Ludwigs-Universität

Freiburg, Freiburg, Germany

${ }^{\ddagger}$ These authors have contributed equally to this work.

Received: 14 October 2016 Accepted: 22 December 2016

Published: 09 January 2017

Citation:

Arias MA, Santiago L, Costas-Ramon S, Jaime-Sánchez $P$,

Freudenberg $M$, Jiménez De

Bagüés MP and Pardo J (2017)

Toll-Like Receptors 2 and 4

Cooperate in the Control of the Emerging Pathogen Brucella microti.

Front. Cell. Infect. Microbiol. 6:205.

doi: 10.3389/fcimb.2016.00205
Toll-like receptors (TLRs) recognize pathogen-derived molecules and play a critical role during the host innate and adaptive immune response. Brucella spp. are intracellular gram-negative bacteria including several virulent species, which cause a chronic zoonotic infection in a wide range of mammalian hosts known as brucellosis. A new Brucella species, Brucella microti, was recently isolated from wild rodents and found to be highly pathogenic in mice. Using this species-specific model, it was previously found that $\mathrm{CD}^{+}{ }^{+} \mathrm{T}$ cells are required to control this infection. In order to find out the role of TLR-mediated responses in the control of this pathogen, the course of infection of $B$. microti was analyzed over 3 weeks in wild-type (WT) and TLR knock out (KO) mice including TLR2 $2^{-/}, \mathrm{TLR}^{-/-}, \mathrm{TLR}^{-/-}, \mathrm{TLR} 2 \times 4^{-/-}$and TLR $2 \times 4 \times 9^{-/-}$. WT and single TLR2, TLR4 and TLR9 KO mice similarly control infection in liver and spleen. In contrast, bacterial clearance was delayed in TLR $2 \times 4^{-1-}$ and TLR $2 \times 4 \times 9^{-1-}$ mice at 7 and 14 days post-infection. This defect correlated with impaired maturation and pro-inflammatory cytokine production in B. microti-infected dendritic cells from TLR $2 \times 4^{-/-}$and TLR $2 \times 4 \times 9^{-/-}$mice. Finally, it was found that Tc cells from TLR $2 \times 4^{-1-}$ and TLR2 $\times 4 \times 9^{-1-}$ mice showed reduced ability to inhibit growth of $B$. microti in macrophages, suggesting the involvement of TLR2 and 4 in the generation of specific Tc cells. Our findings indicate that TLR2 and TLR4 are required to control $B$. microti infection in mice and that this effect could be related to its participation in the maturation of dendritic cells and the generation of specific $\mathrm{CD} 8^{+}$Tc cells.

Keywords: Brucella, toll-like receptors, mouse model, granzyme B, dendritic cells

\section{INTRODUCTION}

The genus Brucella are Gram-negative facultative intracellular pathogens capable of infecting a variety of hosts, causing the worldwide zoonosis known as brucellosis (Franco et al., 2007). This genus consists of several species, which differ mainly in their host preference and it has been traditionally classified into 6 species B. melitensis, B. suis, B. abortus, B. neotomae, B. ovis, and B. canis (Godfroid et al., 2005, 2011). Recently new species have been discovered including B. ceti 
and $B$. pinnipedialis, isolated from cetacean and pinniped species (Foster et al., 2007), and B. inopinata isolated from a human breast implant (De et al., 2008; Scholz et al., 2010).

B. microti, a new species originally isolated from the common vole and later on from the red fox and from soil (Scholz et al., 2008a,b, 2009; Al Dahouk et al., 2012), is the first one found to be highly pathogenic in mice (Jiménez de Bagüés et al., 2011; Arias et al., 2014). In addition, it is able to cause sepsis in C57BL/6 mice (Arias et al., 2014). These results suggest that B. microti is an emergent pathogen that represents a biologically relevant tool to study Brucella pathogenesis and host immunity in mouse models. In contrast to this novel Brucella spp., experimental infection of mice with the same doses of classical Brucella spp. like B. melitensis, B. abortus or B. suis or with the new ones B. ceti and $B$. pinnipedialis leads to a typical replication pattern in the spleen and liver, characterized by a multiplication phase until the number of bacteria reaches its maximum (acute phase), followed by a chronic plateau phase and a declining phase that ends by the clearing of the bacteria in both organs. The duration of these phases depends on the route and the dose of the inoculum and the chronic phase can last more than 20 weeks (Montaraz and Winter, 1986; Edmonds et al., 2002; Abdou et al., 2013; Nymo et al., 2016). None of the classical Brucella spp. are pathogenic for the mouse at doses at which $B$. microti shows high pathogenicity.

Recognition of pathogen-associated molecular patterns (PAMPs) by pattern recognition receptors (PRRs) is the first line of defense involved in the generation of an immune response against infection. This process activates intracellular signaling cascades that culminate in gene activation and production of inflammatory cytokines, chemokines, and co-stimulatory molecules (Kawai and Akira, 2007). The Toll-Like Receptor (TLR) family is the major and most extensively studied class of PRRs (Takeuchi and Akira, 2010). Ten human and 12 murine TLRs have been identified (Akira et al., 2006), which recognize both intracellular and extracellular PAMPs. TLRs 1, 2, 4, 5, 6, and 11 are expressed on the cell membrane, meanwhile TLRs 3, 7,8 , and 9 are located in intracellular endosomes (Sabroe et al., 2008; Kawai and Akira, 2011). They are expressed on a wide range of cell types including dendritic cells, macrophages, B and $\mathrm{T}$ cells, natural killer (NK) cells as well as in cells from nonhematopoietic origin like endothelial cells, epithelial cells and fibroblasts. Regarding their PAMP specificity, TLR2 recognizes a wide array of microbial molecules like bacterial lipotechoic acid, peptidoglycan and lipoproteins, viral hemagglutinin and yeast polysaccharides (Lewis et al., 2012). TLR4 recognizes LPS (from Gram-negative bacteria) and several viral envelop proteins (Hoshino et al., 1999; Takeda and Akira, 2005; Tsujimoto et al., 2008). TLR5 recognizes flagellin, presented in motile bacteria such as Salmonella spp. (Andersen-Nissen et al., 2007) and TLR3, TLR7, TLR8, and TLR9 recognize nucleic acids derived from viruses and bacteria (Akira et al., 2006). All TLRs also recognize endogenous ligands during inflammatory and autoimmune diseases.

Brucella spp. are able to colonize host macrophages, avoiding the immune response and establishing a chronic infection (Baldwin and Goenka, 2006; Gorvel, 2008; Seleem et al., 2008). Using B. abortus and B. melitensis, it was found that dendritic cells, macrophages and CD8 ${ }^{+} \mathrm{T}$ cells (Oliveira and Splitter, 1995; Copin et al., 2007; Macedo et al., 2008; Salcedo et al., 2008) are the key components of the host cellular immunity to control infection in mouse models. The role of TLRs in Brucella infection has been investigated in mouse models utilizing classical Brucella species including B. abortus (Campos et al., 2004; Huang et al., 2005; Weiss et al., 2005; Barquero-Calvo et al., 2007; Macedo et al., 2008; de Almeida et al., 2013), B. melitensis (Copin et al., 2007) and B. ovis (Vieira et al., 2013). However, the role of TLRs during infection with a mouse specific species like $B$. microti is still unknown.

We have previously shown that $\mathrm{CD}^{+} \mathrm{T}$ cells are involved in the control of $B$. microti infection in mice (Jiménez de Bagüés et al., 2011; Arias et al., 2014). We have now analyzed the role of TLR2, TLR4 and TLR9 in the control of B. microti infection and found that in vivo TLR2 and TLR4 cooperate to eliminate this pathogen, while TLR9 is dispensable to control the infection. The implication of TLR 2 and 4 in the control of the infection seems to be related to the generation of anti-bacterial $\mathrm{CD} 8^{+} \mathrm{T}$ cell activity and the maturation of dendritic cells, including the production of pro-inflammatory cytokines.

\section{EXPERIMENTAL PROCEDURES}

\section{Mouse Strains}

Inbred C57BL/10 (WT B10) (Janvier Laboratories, France), and mouse strains deficient for Toll Like Receptor 2 (TLR2 ${ }^{-/}$), 4 (TLR $^{-/-}$), 9 (TLR9 $^{-/-}$), 2 and 4 (TLR $2 \times 4^{-/-}$) and 2 , 4 , and 9 (TLR $2 \times 4 \times 9^{-/-}$) were kindly provided by Marina Freudenberg from the Max-Planck-Institute for Immunobiology and Epigenetics, Freiburg and bred at Animal facilities of the CITA. Their genotypes were analyzed as described (Pardo et al., 2008). Eight to twelve weeks old mice were used in all experiments. Animal experimentation was approved by the Ethics Committee for Animal Experimentation from the CITA (number 2011/01).

\section{Bacterial Strain and Determination of CFU}

B. microti strain CCM 4915 (Jiménez de Bagüés et al., 2011) was used in all experiments. It was grown to stationary phase in tryptic soy broth (Difco), with shaking, at $37^{\circ} \mathrm{C}$. The number of living bacteria in a sample was determined by counting the CFU after plating serial dilutions onto tryptic soy agar plates as described previously (Jiménez de Bagüés et al., 2011). In addition, the smooth phenotype of the strain was verified in all cases by crystal violet staining (Jiménez de Bagüés et al., 2010).

\section{Replication of Brucella microti In vivo}

A sublethal dose $\left(10^{5} \mathrm{CFU}\right)$ of $B$. microti was injected intraperitoneally (ip) and, at different time points, mice were euthanized by $\mathrm{CO} 2$ asphyxiation and blood, spleen, and liver samples were collected aseptically. Organs were weighed, homogenized, serially diluted in PBS, plated onto tryptic soy agar and incubated $48 \mathrm{~h}$ at $37^{\circ} \mathrm{C}$ for determining the number of viable Brucella organisms. 


\section{Isolation of Tc Cells from Spleen}

WT B10 mice and mice deficient in TLR 2, TLR 4, and TLR 9 were infected with a sublethal dose of $B$. microti $\left(10^{5} \mathrm{CFU}\right)$ ip. After 7 days $\mathrm{CD}^{+}(\mathrm{Tc})$ cells were positively selected from spleen using anti-CD8-MicroBeads and autoMACS (Miltenyi Biotec, Spain). Finally, Tc cells were resuspended in DMEM supplemented with $10 \%$ of inactivated fetal calf serum (FCS) containing $30 \mu \mathrm{g} / \mathrm{ml}$ of gentamicin before using them in different assays.

\section{Intracellular Expression of Granzyme B}

Intracellular expression of granzyme B in MACS-enriched Tc cells was analyzed by FACS as previously described (Joeckel et al., 2011). Prior to the first staining step cells were incubated with anti(a)-FcR-antibody (clone 2.4G2) to avoid unspecific stainings. Rabbit immune serum (IS) specific for mouse gzmB (a-mgzmB) has been previously described (Joeckel et al., 2011).

\section{Replication of Brucella microti in Bone Marrow Derived Macrophages (BMDM)}

Macrophages were differentiated from mouse bone marrow (BM) as previously described (Aporta et al., 2012). Briefly, cells were aseptically collected from bone marrow and resuspended in DMEM supplemented with $10 \%$ of inactivated FCS, $2 \mathrm{mM}$ glutamine, $5 \%$ of inactivated horse serum and $10 \%$ supernatant of L-929 cell cultures as source of M-CSF. Cells were seeded at a density of $1 \times 10^{6}$ cells $/ \mathrm{ml}$ and allowed to differentiate for 6 days at $37^{\circ} \mathrm{C}$ and $5 \% \mathrm{CO}_{2}$. At day 6 macrophages were used for the different experiments. Cell cultures contained more than $90 \%$ of

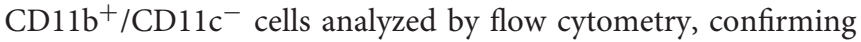
the macrophage identity of cells.

For replication experiments in vitro $4 \times 10^{5}$ macrophages/well were seeded in 24 well plates, infected with $B$. microti at a multiplicity of infection (MOIs) of 25:1 and incubated for $45 \mathrm{~min}$ at $37^{\circ} \mathrm{C}$, in a $5 \% \mathrm{CO}_{2}$ atmosphere. At this time point enriched Tc from WT or KO mice were added at 5:1 ratio. Subsequently, medium was removed, cells were washed with PBS and further incubated with complete DMEM medium containing $30 \mu \mathrm{g} / \mathrm{ml}$ of gentamycin. After $24 \mathrm{~h}$ macrophages were lysed with $0.1 \%$ of Triton-X100 and Brucella CFU number was determined by dilution plating.

\section{Generation of BM-Derived Dendritic Cells, BMDCs}

DCs were generated from bone marrow cells using wild-type C57BL/10, $\mathrm{TLR}^{-/-}, \mathrm{TLR}^{-/-}, \mathrm{TLR}^{-/-}, \mathrm{TLR} 2 \times 4^{-/-}$, TLR $2 \times 4 \times 9^{-/-}$and MyD88 $8^{-/-}$mice, in RPMI 1640 medium containing $10 \%$ of FCS serum, $100 \mathrm{U} / \mathrm{ml}$ of penicillin/streptomycin, $50 \mathrm{mM}$ of $2-\mathrm{ME}$, and $10 \%$ of supernatant of X63Ag8653 cell cultures as source of GM-CSF (Zal et al., 1994) (DC medium). Cells were cultured on $100 \mathrm{~mm}$ petri dishes $\left(1 \times 10^{6}\right.$ cells $/ 10 \mathrm{ml} \mathrm{DC}$ culture medium). On days 2 and 4, the cell medium was refreshed and, on day 6, cells showed differentiated morphology and expressed the DC markers $\mathrm{CD}_{11 c^{+}}$, MHC class II (MHCII) low and CD40 low (d Jata not shown), confirming their identity as immature DCs.

\section{Replication of $B$. microti in BMDC}

For in vitro $B$. microti infection experiments $4 \times 10^{5} \mathrm{DC}$ were seeded in 24 well plates and infected with $B$. microti at a MOIs of $25: 1$ for $45 \mathrm{~min}$ at $37^{\circ} \mathrm{C}, 5 \% \mathrm{CO}_{2}$. Subsequently, medium was removed, cells were washed with $\mathrm{PBS}$ and further incubated with complete RPMI medium containing $30 \mu \mathrm{g} / \mathrm{ml}$ of gentamycin. After 1.5, 24, and $48 \mathrm{~h}$ DC were lysed with Triton-X $0.1 \%$ and CFU number was determined. At each time supernatants were collected and the levels of TNF $\alpha$ and IL- 6 were measured employing commercial ELISA kits (eBiocience).

\section{Analysis of BMDC Maturation}

To analyze DC maturation, BMDC were stimulated for $24 \mathrm{~h}$ with $E$. coli-derived LPS $(1 \mu \mathrm{g} / \mathrm{ml})$ or heat killed B. microti (HKBM; 100 bacteria/cell). Subsequently, the expression of MHCII, CD40, CD86 and CD80 was analyzed on CD11c ${ }^{+}$cells using MHCII-APC, CD40-APC, CD86-FITC, CD80-FITC and CD11c-PE antibodies (Miltenyi Biotec). Samples were fixed with $4 \%$ PFA and analyzed by flow cytometry using a FACSCalibur flow cytometer (BD Biosciences).

\section{Statistical Analyses}

Statistical analysis was performed using GraphPad Prism software. The difference between means of three or more independent groups was performed using one-way ANOVA test with Bonferroni's post-test. The results are given as the confidence interval (p), and are considered significant when $P<0.05$. Biological replicates are considered as the number of individual mice.

\section{RESULTS}

\section{TLR2 and TLR4 Cooperate to Control B. microti infection In vivo}

In order to analyze the role of TLR2 and TLR4 in the control of B. microti infection, WT B10, TLR $2^{-/-}, \mathrm{TLR} 4^{-/-}$and TLR $2 \times 4^{-/-}$mice were infected ip with a sublethal dose $\left(10^{5}\right.$ cfu) of $B$. microti and bacterial load was determined in spleen and liver 3, 7, 14, and 21 days after infection. As shown in Figure 1, bacterial clearance was delayed in TLR $2 \times 4^{-/-}$mice compared with WT B10 mice. The absence of either TLR2 or TLR4 did not affect bacterial clearance.

By day 3, the time of maximum bacterial load, no differences were found between the different animal groups. However, significant differences were found between WT B10 and TLR $2 \times 4^{-1-}$ mice in spleen and liver after 7 days, time after which wild type animals began to clear infection. The differences between the two groups were less pronounced, but still significant, after 14 days. No differences were found anymore between the different groups after 21 days.

\section{TLR9 Is Not Required to Control B. microti infection}

Our results indicate that in vivo both TLR2 and 4 are required for the early control of $B$. microti replication. Previous works have shown that TLR9 is involved in the early control of $B$. ovis and B. abortus infection. Thus, we decided to analyze the role of TLR9 
in the control of $B$. microti infection. In this experiment bacterial replication was only analyzed after 7 and 14 days of infection, times after which significant differences were found between WT B10 and TLR $2 \times 4^{-/-}$mice.

As shown in Figure 2 bacterial load was significantly higher in spleen and liver of TLR $2 \times 4^{-/-}$and TLR $2 \times 4 \times 9^{-/-}$mice compared to WT B10 mice. No differences were found between WT B10 and TLR9 ${ }^{-/}$mice. In addition, bacterial replication was similar in TLR $2 \times 4^{-/-}$and TLR $2 \times 4 \times 9^{-/-}$mice, indicating that TLR9 does not play any role in the control of B. microti infection.

\section{Replication of B. microti and Cytokine Production in BMDC from Mice Deficient in TLR2, TLR4 and TLR9}

Several TLRs are involved in the activation and maturation of dendritic cells by classical Brucella spp. (Campos et al., 2004; Huang et al., 2005; Weiss et al., 2005; Barquero-Calvo et al.,
2007; Copin et al., 2007; Macedo et al., 2008; de Almeida et al., 2013). Thus, we decided to analyze the role of TLR2, TLR4 and TLR9 in DC activation and maturation after B. microti infection in vitro. First, we analyzed if DC from mice deficient in the different TLRs failed to produce Th1 polarizing proinflammatory cytokines after $B$. microti infection, a critical step to further induce the activation of $\mathrm{T}$ cell responses against intracellular pathogens. WT B10, TLR2 ${ }^{-/-}$, TLR4 $4^{-/-}$, TLR9 ${ }^{-/-}$, TLR $2 \times 4^{-/-}$and TLR $2 \times 4 \times 9^{-/-}$BMDCs were infected with B. microti at a MOI:25 and production of TNF $\alpha$ and IL6 as well as bacterial replication were determined after 24 and $48 \mathrm{~h}$ (Figure 3).

As shown in Figures $\mathbf{3 A , B}$, the absence of either TLR2 or TLR4 significantly reduced the production of TNF $\alpha$ (Figure 3A) and IL6 (Figure 3B) after 24 and $48 \mathrm{~h}$ of infection. TLR9 deficiency did not affect TNF $\alpha$ production and only slightly reduced IL6 generation. When TLR2 and TLR4 or TLR2, TLR4 and TLR9 were absent, TNF $\alpha$ and IL6 generation was reduced to basal (non-stimulated control) levels.
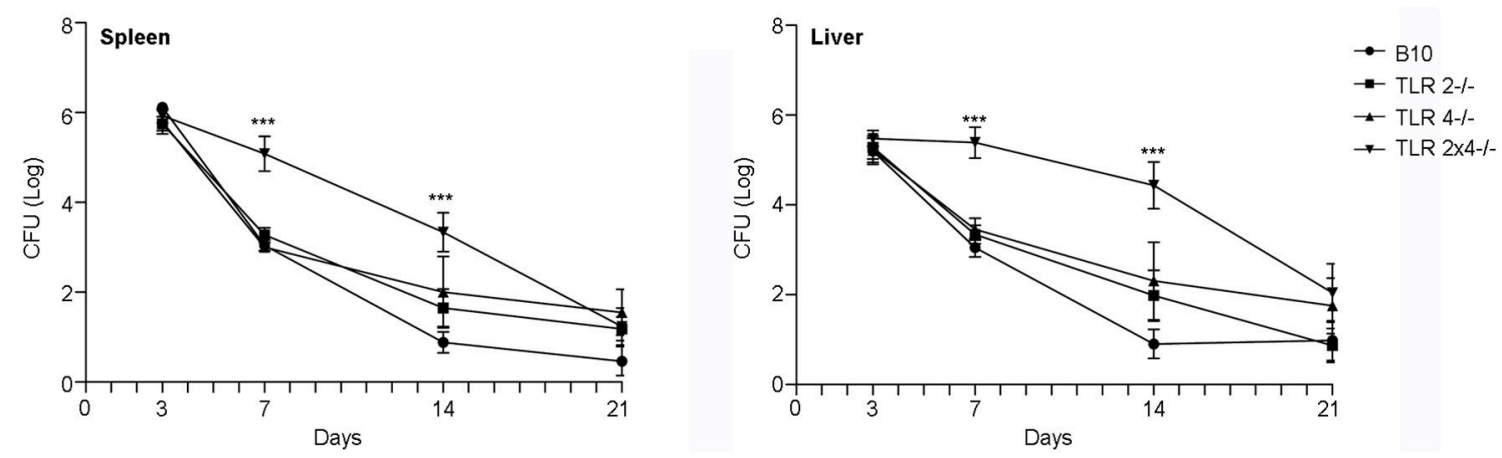

FIGURE 1 | The absence of both TLR2 and 4 affects the control of $B$. microti infection in spleen and liver. TLR2 ${ }^{-/-}$, TLR $4^{-/-}$and TLR $2 \times 4^{-/-}$mice were infected i.p. with B. microti ( $\left.10^{5} \mathrm{CFU}\right)$ and the number of CFU in spleen and liver was determined $3,7,14$, or 21 days later. Data are presented as mean $\pm \mathrm{SEM}$ of 10-25 biological replicates performed in 4 independent experiments; Statistical analyses was performed by one-way ANOVA test with Bonferroni's post-test. ${ }^{\star * \star} P<0.001$, comparing each group with the control group (WT B10).
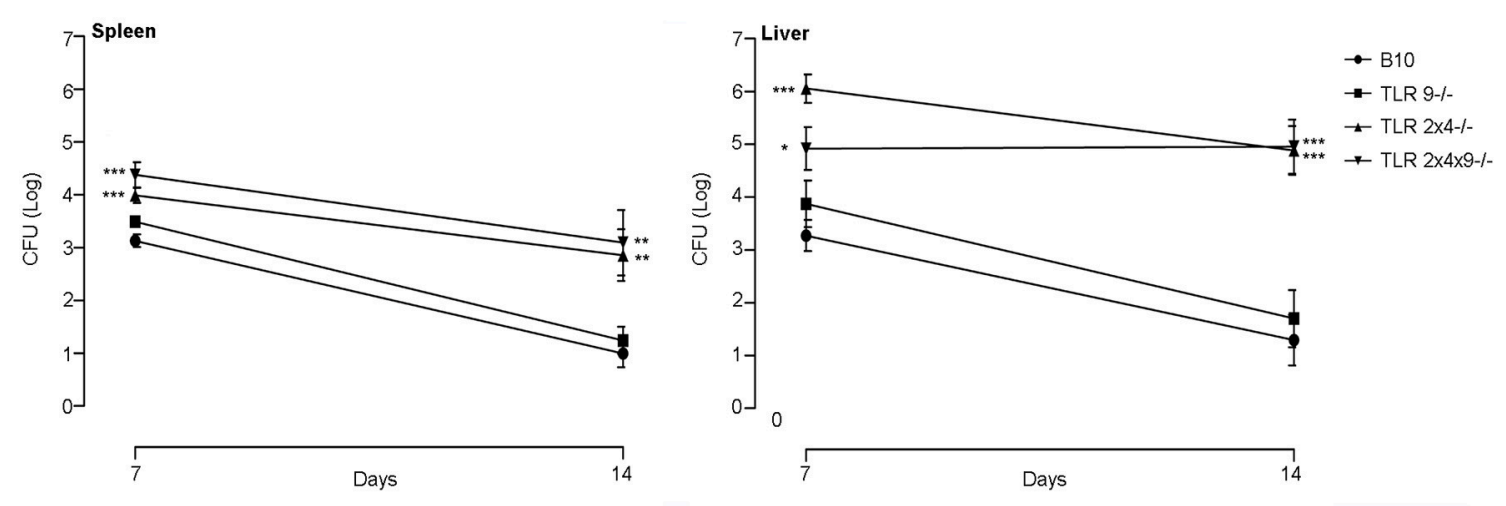

FIGURE 2 | TLR9 is not necessary for the control of $B$. microti infection in spleen and liver. WT B10, TLR9 ${ }^{-/-}$, TLR $2 \times 4^{-/-}$and TLR $2 \times 4 \times 9^{-/-}$mice were infected i.p. with B. microti $\left(10^{5} \mathrm{CFU}\right)$ and the number of CFU in spleen and liver was determined 7 and 14 days later. Data are presented as mean \pm SEM of $7-12$ biological replicates performed in 2 independent experiments; Statistical analyses was performed by one-way ANOVA test with Bonferroni's post-test. ${ }^{*} P<0.05$; ${ }^{\star \star} P<0.01 ;{ }^{\star \star \star} P<0.001$, comparing each group with the control group (WT B10). 

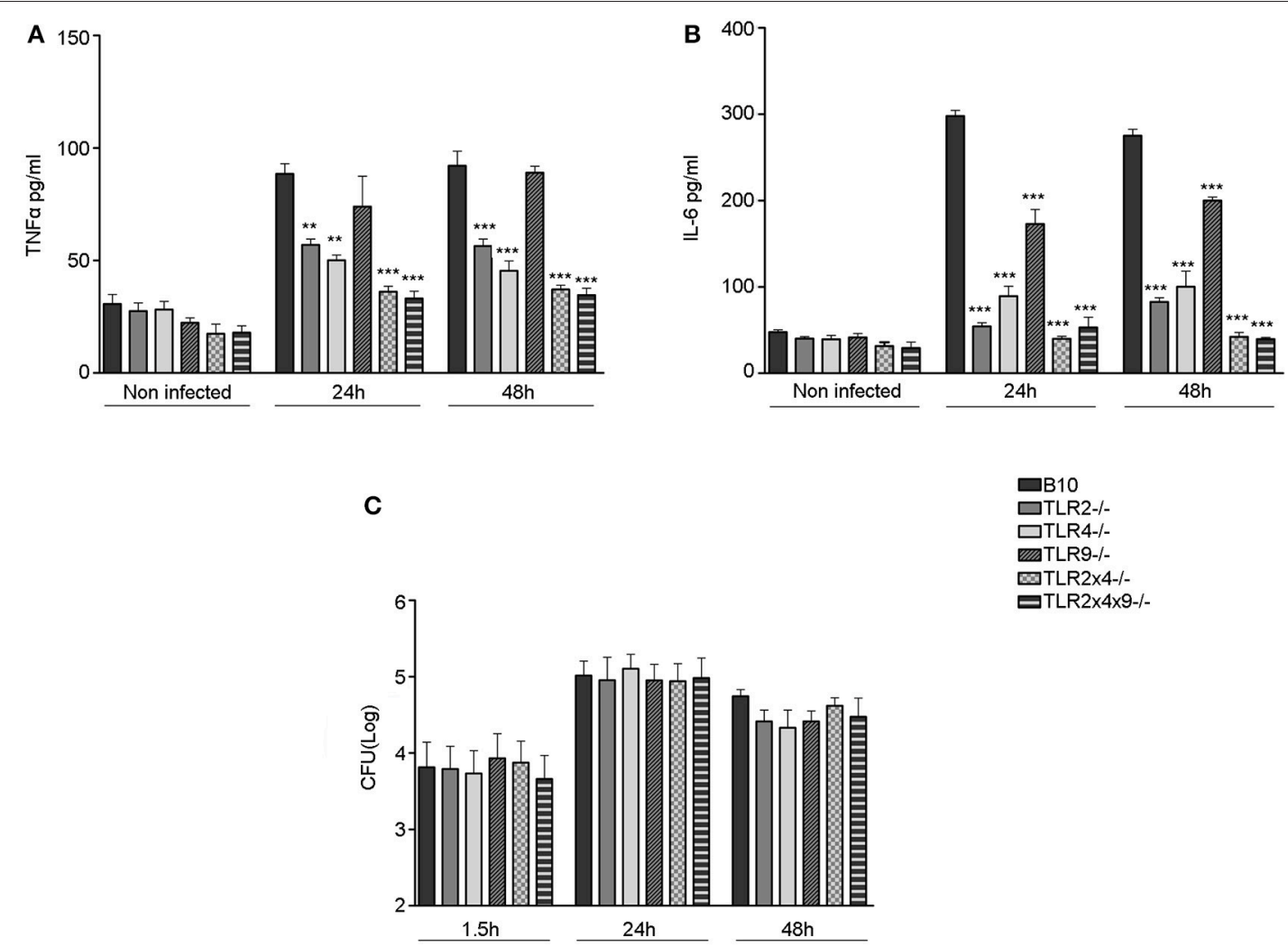

FIGURE 3 | Replication of B. microti in BMDC and cytokine production in BMDC deficient in TLR2, TLR4 and TLR9. $4 \times 10^{5}$ BMDC from WT B10, $\mathrm{TLR}^{-/}{ }^{-}$, TLR4 ${ }^{-/-}, \mathrm{TLR}^{-/-}$, TLR $2 \times 4^{-/-}$or TLR $2 \times 4 \times 9^{-/-}$mice were infected with $B$. microti (MOI $\left.25: 1\right)$ for 45 min and, subsequently, cells were washed with PBS and further incubated with RPMl $10 \%$ FCS containing $30 \mu \mathrm{g} / \mathrm{ml}$ of gentamycin. (A,B) After 24 and $48 \mathrm{~h}$ of infection cell culture supernatants were collected and the levels of TNF $\alpha$ (A) and IL-6 (B) were measured by ELISA. (C) After 1.5, 24, and 48 $\mathrm{h}$ DC were lysed with Triton-X $0.1 \%$ and CFU number was determined as indicated in materials and methods. Statistical analyses was performed by one-way ANOVA test with Bonferroni's post-test. ${ }^{\star \star} P<0.01$; ${ }^{\star \star \star} P<0.001$, comparing each group with the control group (WT B10).

These differences were not due to different levels of intracellular B. microti since entry and replication of B. microti (Figure 3C) was not affected by TLR deficiency.

\section{Role of TLR2, TLR4 and TLR9 in BMDC Maturation}

Next we analyzed the role of TLR2, TLR4 and TLR9 in the maturation of DC, another key step to control intracellular bacterial replication.

BM-derived DCs from WT and TLR KO mice were stimulated with E. coli LPS or with heat killed B. microti (HKBM) and cell surface expression of CD40, CD80, CD86 and MHC-II was analyzed on $\mathrm{CD} 11 \mathrm{c}^{+}$cells. In comparison with control nonstimulated cells, BMDC from WT mice stimulated with LPS or HKBM showed enhanced expression of CD40 (Figure 4A), CD80 (Figure 4B), CD86 (Figure 4C) and MHC-II (Figure 4D), confirming the generation of mature DCs. A similar maturation profile was observed in TLR2 ${ }^{-/-}$, TLR4 $4^{-/}$or TLR9 ${ }^{-/-}$DCs stimulated with HKBM. As expected, stimulation with LPS did not increase expression of these markers in DCs from TLR4 ${ }^{-/-}$ mice. The absence of TLR 2 and 4 or TLR2, 4 , and 9 significantly reduced the expression of the maturation markers in DC, confirming that TLR2 and TLR4 are involved in DC activation and maturation.

\section{B. microti-Specific Ex vivo Tc Cells from Mice Deficient in TLR2 and TLR4 Show a Lower Capacity to Block B. microti Replication in BMDM}

Finally, we analyzed if impaired maturation of DC from TLR2, 4 and 9 deficient mice, correlated with a reduced ability to activate $B$. microti-specific $\mathrm{CD} 8^{+}$Tc cell responses during in vivo infection. We have previously shown that $\mathrm{CD}^{+} \mathrm{T}$ cells are involved in the control B. microti infection in vivo as well as in macrophages in vitro and, thus, defective control of infection observed in the absence of TLR2 and TLR4 could be related with a lower generation of $B$. microti-specific $\mathrm{CD}^{+}$Tc cells (Arias et al., 2014). WT B10, TLR2-/-, TLR4 ${ }^{-/-}$, TLR9 ${ }^{-/-}$, TLR $2 \times 4^{-/-}$and TLR $2 \times 4 \times 9^{-/-}$mice were infected with a sublethal doses ( $10^{5} \mathrm{CFU}$ ip) of $B$. microti and, 7 days later, $\mathrm{CD}^{+}$cells from spleen were enriched by MACS and incubated with $B$. microti-infected macrophages. As shown in Figure 5, bacterial growth was significantly reduced by $\mathrm{CD}^{+} \mathrm{T}$ cells from 


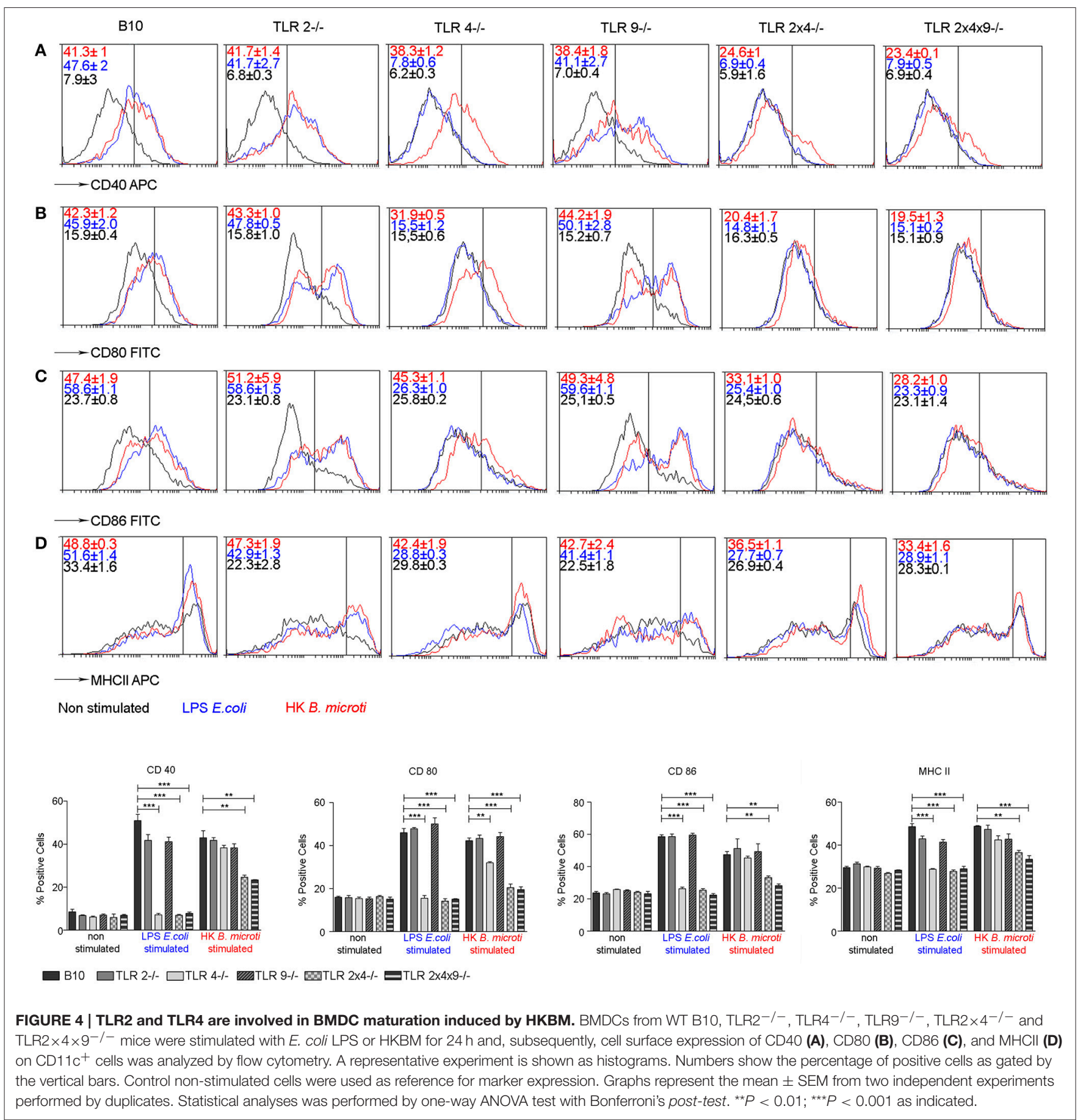

WT, TLR2 $2^{-/-}$TLR$^{-/-}$or TLR9 ${ }^{-/-}$deficient mice. In contrast, bacteria replicated significantly higher in macrophages incubated with $\mathrm{CD}^{+} \mathrm{T}$ cells from TLR $2 \times 4^{-/-}$or TLR $2 \times 4 \times 9^{-/-}$mice, confirming a defect in the anti-bacterial activity of $\mathrm{CD} 8^{+} \mathrm{T}$ cells in the absence of TLR2 and TLR4.

This defect was not due to a reduced activation of $\mathrm{CD}^{+}$ $\mathrm{T}$ cells since cells from WT and TLR KO mice expressed similar levels of the cytotoxic activation marker granzyme B (Figure 5B).

\section{DISCUSSION}

B. microti is new atypical Brucella species, highly pathogenic in mice, that causes bacterial sepsis and death (Jiménez de Bagüés et al., 2010; Arias et al., 2014). We have previously found that adaptive $\mathrm{T}$ and $\mathrm{B}$ cell responses are required to efficiently control B. microti infection in mice (Jiménez de Bagüés et al., 2011). In this work, we have analyzed the role of TLR2, TLR4 and TLR9, the main receptors within the TLR family involved in the control 


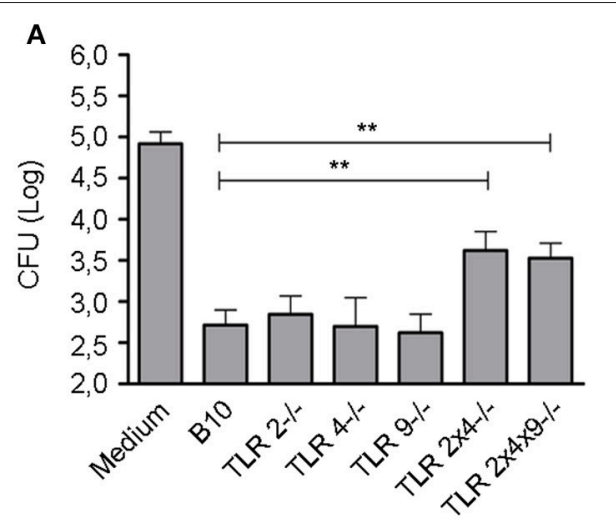

B

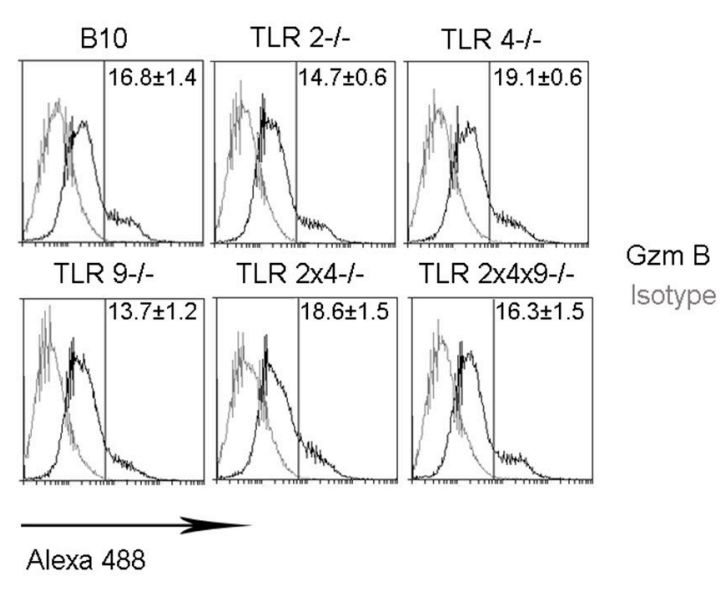

FIGURE 5 | B. microti- specific ex vivo Tc cells from mice lacking TLR2 and TLR4 show a lower capacity to inhibit B. microti replication in BMDM. (A) WT B10, TLR2 ${ }^{-/-}$, TLR4 ${ }^{-/-}$, TLR9 ${ }^{-/-}$, TLR2 $\times 4^{-/-}$and TLR2 $\times 4 \times 9^{-/-}$mice were infected with B. microti i.p. (10 ${ }^{5}$ cfu). Seven days later, CD8 ${ }^{+}$cells were enriched from spleen using MACS and incubated with BMDM from WT B10 mice infected with B. microti. After $24 \mathrm{~h}$, cells were lysed and the number of CFU was determined. Data are presented as mean \pm SEM from three independent experiments performed by triplicates. Statistical analyses was performed by one-way ANOVA test with Bonferroni's post-test. ${ }^{\star \star} P<0.01$, comparing each group with the group treated with WT B10 Tc cells. (B) Intracellular expression of granzyme B was analyzed in MACS-enriched $\mathrm{CD} 8^{+}$cells. A representative experiment from two independent studies is shown.

of classical Brucella spp., during B. microti infection. We have found that TLR2 and TLR4 cooperate in the early control of this infection, while TLR9 is dispensable. At later stages, all mice control infection and compensate for the lack of TLR2 and TLR4 by additional unknown mechanisms.

The role of TLRs in the control of B. microti infection seems to be different from classical Brucella spp. While TLR9 is important in host defense against B. abortus (Macedo et al., 2008), B. melitensis (Copin et al., 2007) and B. ovis (Vieira et al., 2013), our data show that TLR9 is not necessary for the control of B. microti infection in mice. In contrast, TLR2 and TLR4 cooperate for controlling $B$. microti infection, while it has been previously reported that TLR2 does not play any role in host defense against B. abortus, B. melitensis, and B. ovis (Weiss et al., 2005; Copin et al., 2007; Vieira et al., 2013). Concerning the role of TLR4 in the control of classical Brucella spp., contradictory findings have been reported. Some works indicate that TLR4 participates in host defense against B. melitensis (Copin et al., 2007) and B. abortus (Campos et al., 2004), but others indicate that both TLR4 and TLR2 are dispensable for the control of $B$. abortus infection (Weiss et al., 2005; Barquero-Calvo et al., 2007).

The differences found concerning the participation of TLR2 and TLR4 in the control of B. microti and classical Brucella spp., might be related to the different composition of TLR ligands expressed by novel and classical species. Supporting this hypothesis, in contrast to B. microti, classical Brucella spp. do not induce sepsis in animal models. This is likely related to the composition of LPS in the classical species that differs from the conventional LPS structure found in other gram(-) bacterial pathogens (Cardoso et al., 2006). In this regard, it has been shown that the core-lipid A moiety of LPS of B. microti is different from classical Brucella spp., although its ability to activate TLR4 has not been tested yet (Zygmunt et al., 2012). Further supporting this hypothesis, it is well known that TLR2 and TLR4 are crucial in host defense against several bacterial pathogens that, like B. microti, cause sepsis like Staphylococcus aureus, Streptococcus pneumoniae (Takeuchi et al., 2000; Dessing et al., 2008), Klebsiella pneumoniae (Schurr et al., 2005), Haemophillus influenza (Wang et al., 2002) and Acinetobacter baumanii (Knapp et al., 2006).

Concerning TLR2, it is well known that lipoproteins (the main TLR2 ligands) expressed by classical Brucella spp. are poor activators of innate immune responses (Olsen and Palmer, 2014). Thus, it is tempting to speculate that B. microti could express lipoproteins that would activate TLR2-related responses more efficiently than those activated by lipoproteins expressed in classical Brucella spp. However, more experiments are required to confirm this hypothesis.

What would the impact be of TLR2 and TLR4 deficiency on the generation of adaptive immune responses during $B$. microt $i$ infection? Our group has previously found that $\mathrm{CD}^{+} \mathrm{Tc}$ cells are also required to control B. microti infection (Arias et al., 2014). We have now shown that Tc cells from mice lacking TLR2 and TLR4 show a lower capacity to abrogate B. microti replication in BMDMs-infected cells. The inability of ex vivo TLR $2 \times 4^{-/-}$mice-derived Tc cells to block B. microti replication in BMDM seems to be related to impaired dendritic cell maturation. Interestingly, Tc cells from TLR $2 \times 4^{-/-}$mice do not present any in vivo defect in activation, as shown by gzmB intracellular expression that is similar in Tc cells from WT and TLR $2 \times 4^{-/-}$mice. Clonal expansion and development of cytotoxic function (i.e., gzmB) in $\mathrm{CD}^{+} \mathrm{T}$ cells requires three independent signals: (a) Ag presentation, (b) co-stimulation, and (c) IL-12 or adjuvant (Curtsinger et al., 2003). During the maturation process, DC enhance their Ag presenting ability and prime $\mathrm{T}$ cells by up-regulating cell surface MHCII and the CD40, CD80 and CD86 co-stimulatory molecules (Macedo et al., 2008) (signals 1 and 2). However, the acquisition of cytotoxic capacity is only dependent on IL-12 (signal 3) (Curtsinger et al., 
2003). Thus, our results might indicate that TLR2 and TLR4 would participate in DC maturation (signals 1 and 2), but not in the production of IL12 (signal 3). However, this hypothesis would need further experimental validation, which is out of the scope of the present work. Altogether it seems that the reduced capacity of Tc from TLR $2 \times 4$ deficient mice to abrogate the replication of $B$. microti in BMDM might be related to a lower generation of $B$. microti-specific Tc cells due to impairment in DC maturation.

In conclusion, TLR2 and TLR 4 cooperate to control B. microti infection in mice by a mechanism that seems to be dependent on DC maturation and generation of specific B. microti $\mathrm{CD} 8^{+}$ Tc cells. This finding provides more insights into the control of a novel emerging species of the Brucella genus and advises caution when interpreting the mechanisms involved in host-pathogen interaction, using non-specific pathogens of this bacterial genus.

\section{AUTHOR CONTRIBUTIONS}

Conceived and designed the experiments: MJ, JP. Performed the experiments: MA, LS, SC-R, PJ-S. Analyzed the data: MA, LS, SC-

\section{REFERENCES}

Abdou, E., Deredjian, A., Jiménez de Bagüés, M. P., Köhler, S., and Jubier-Maurin, V. (2013). RegA, the regulator of the two-component system RegB/RegA of Brucella suis, is a controller of both oxidative respiration and denitrification required for chronic infection in mice. Infect. Immun. 81, 2053-2061. doi: 10.1128/IAI.00063-13

Akira, S., Uematsu, S., and Takeuchi, O. (2006). Pathogen recognition and innate immunity. Cell 124, 783-801. doi: 10.1016/j.cell.2006.02.015

Al Dahouk, S., Hofer, E., Tomaso, H., Vergnaud, G., Le Fleche, P., Cloeckaert, A., et al. (2012). Intraspecies biodiversity of the genetically homologous species Brucella microti. Appl. Environ. Microbiol. 78, 1534-1543. doi: 10.1128/AEM.06351-11

Andersen-Nissen, E., Smith, K. D., Bonneau, R., Strong, R. K., and Aderem, A. (2007). A conserved surface on Toll-like receptor 5 recognizes bacterial flagellin. J. Exp. Med. 204, 393-403. doi: 10.1084/jem.20061400

Aporta, A., Arbues, A., Aguilo, J. I., Monzon, M., Badiola, J. J., de Martino, A., et al. (2012). Attenuated Mycobacterium tuberculosis $\mathrm{SO}_{2}$ vaccine candidate is unable to induce cell death. PLOS ONE 7:e45213. doi: 10.1371/journal.pone. 0045213

Arias, M. A., Jiménez de Bagüés, M. P., Aguilo, N., Menao, S., HervasStubbs, S., de Martino, A., et al. (2014). Elucidating sources and roles of granzymes A and B during bacterial infection and sepsis. Cell Rep. 8, 420-429. doi: 10.1016/j.celrep.2014.06.012

Baldwin, C. L., and Goenka, R. (2006). Host immune responses to the intracellular bacteria Brucella: does the bacteria instruct the host to facilitate chronic infection? Crit. Rev. Immunol. 26, 407-442. doi: 10.1615/CritRevImmunol.v26.i5.30

Barquero-Calvo, E., Chaves-Olarte, E., Weiss, D. S., Guzman-Verri, C., ChaconDiaz, C., Rucavado, A., et al. (2007). Brucella abortus uses a stealthy strategy to avoid activation of the innate immune system during the onset of infection. PLoS ONE 2:e631. doi: 10.1371/journal.pone.0000631

Campos, M. A., Rosinha, G. M., Almeida, I. C., Salgueiro, X. S., Jarvis, B. W., Splitter, G. A., et al. (2004). Role of Toll-like receptor 4 in induction of cellmediated immunity and resistance to Brucella abortus infection in mice. Infect. Immun. 72, 176-186. doi: 10.1128/IAI.72.1.176-186.2004

Cardoso, P. G., Macedo, G. C., Azevedo, V., and Oliveira, S. C. (2006). Brucella spp. noncanonical LPS: structure, biosynthesis, and interaction
R, PJ-S. Contributed reagents/materials/analysis tools: $\mathrm{MF}, \mathrm{MJ}$, JP. Wrote the paper: MA, LS, MJ, JP.

\section{ACKNOWLEDGMENTS}

Authors thank the animal care staff of CITA for assistance in the animal work and Clara Montolio for helping in animal processing. We would like to acknowledge the use of Servicios Cientifico-Tecnicos (SCT) del CIBA (Instituto Aragones de Ciencias de la Salud, Universidad de Zaragoza, Fundacion IIS Aragón) and Servicos de Apoyo a la Investigación (SAI) de la Universidad de Zaragoza. This work was supported in part by grants SAF2011-25390 and SAF2014-54763-C2-1-R from Spanish Ministry of Economy and Competitiveness and RTA2013-00065-C02-01 from the Spanish Instituto Nacional de Investigaciones Agrarias (INIA), Aragón I+D (ARAID) and Fondo Social Europeo (FSE). MA and LS were supported by a $\mathrm{PhD}$ fellowship from University of Zaragoza/Santander Bank Foundation. LS was also supported by a FPI contract. PJ-S was supported by a PhD fellowship from Government of Aragon. JP was supported by ARAID Foundation. with host immune system. Microb. Cell Fact. 5:13. doi: 10.1186/14752859-5-13

Copin, R., De Baetselier, P., Carlier, Y., Letesson, J. J., and Muraille, E. (2007). MyD88-dependent activation of B220-CD11b+LY-6C+ dendritic cells during Brucella melitensis infection. J. Immunol. 178, 5182-5191. doi: 10.4049/jimmunol.178.8.5182

Curtsinger, J. M., Lins, D. C., and Mescher, M. F. (2003). Signal 3 determines tolerance versus full activation of naive CD8 T cells: dissociating proliferation and development of effector function. J. Exp. Med. 197, 1141-1151. doi: 10.1084/jem.20021910

de Almeida, L. A., Macedo, G. C., Marinho, F. A., Gomes, M. T., Corsetti, P. P., Silva, A. M., et al. (2013). Toll-like receptor 6 plays an important role in host innate resistance to Brucella abortus infection in mice. Infect. Immun. 81, 1654-1662. doi: 10.1128/IAI.01356-12

De, B. K., Stauffer, L., Koylass, M. S., Sharp, S. E., Gee, J. E., Helsel, L. O., et al. (2008). Novel Brucella strain (BO1) associated with a prosthetic breast implant infection. J. Clin. Microbiol. 46, 43-49. doi: 10.1128/JCM.01494-07

Dessing, M. C., Florquin, S., Paton, J. C., and van der Poll, T. (2008). Tolllike receptor 2 contributes to antibacterial defence against pneumolysindeficient pneumococci. Cell. Microbiol. 10, 237-246. doi: 10.1111/j.1462-5822. 2007.01035.x

Edmonds, M. D., Cloeckaert, A., and Elzer, P. H. (2002). Brucella species lacking the major outer membrane protein Omp25 are attenuated in mice and protect against Brucella melitensis and Brucella ovis. Vet. Microbiol. 88, 205-221. doi: 10.1016/S0378-1135(02)00110-4

Foster, G., Osterman, B. S., Godfroid, J., Jacques, I., and Cloeckaert, A. (2007). Brucella ceti sp. nov. and Brucella pinnipedialis sp. nov. for Brucella strains with cetaceans and seals as their preferred hosts. Int. J. Syst. Evol. Microbiol. 57(Pt 11), 2688-2693. doi: 10.1099/ijs.0.65269-0

Franco, M. P., Mulder, M., Gilman, R. H., and Smits, H. L. (2007). Human brucellosis. Lancet Infect. Dis. 7, 775-786. doi: 10.1016/S1473-3099(07) 70286-4

Godfroid, J., Cloeckaert, A., Liautard, J. P., Kohler, S., Fretin, D., Walravens, K., et al. (2005). From the discovery of the Malta fever's agent to the discovery of a marine mammal reservoir, brucellosis has continuously been a re-emerging zoonosis. Vet. Res. 36, 313-326. doi: 10.1051/vetres:2005003

Godfroid, J., Scholz, H. C., Barbier, T., Nicolas, C., Wattiau, P., Fretin, D., et al. (2011). Brucellosis at the animal/ecosystem/human interface 
at the beginning of the 21st century. Prev. Vet. Med. 102, 118-131. doi: 10.1016/j.prevetmed.2011.04.007

Gorvel, J. P. (2008). Brucella: a Mr "Hide" converted into Dr Jekyll. Microbes Infect. 10, 1010-1013. doi: 10.1016/j.micinf.2008.07.007

Hoshino, K., Takeuchi, O., Kawai, T., Sanjo, H., Ogawa, T., Takeda, Y., et al. (1999). Cutting edge: toll-like receptor 4 (TLR4)-deficient mice are hyporesponsive to lipopolysaccharide: evidence for TLR4 as the Lps gene product. J. Immunol. $162,3749-3752$.

Huang, L. Y., Ishii, K. J., Akira, S., Aliberti, J., and Golding, B. (2005). Th1-like cytokine induction by heat-killed Brucella abortus is dependent on triggering of TLR9. J. Immunol. 175, 3964-3970. doi: 10.4049/jimmunol.175.6.3964

Jiménez de Bagüés, M. P., de Martino, A., Quintana, J. F., Alcaraz, A., and Pardo, J. (2011). Course of infection with the emergent pathogen Brucella microti in immunocompromised mice. Infect. Immun. 79, 3934-3939. doi: 10.1128/IAI.05542-11

Jiménez de Bagüés, M. P., Ouahrani-Bettache, S., Quintana, J. F., Mitjana, O., Hanna, N., Bessoles, S., et al. (2010). The new species Brucella microti replicates in macrophages and causes death in murine models of infection. J. Infect. Dis. 202, 3-10. doi: 10.1086/653084

Joeckel, L. T., Wallich, R., Martin, P., Sanchez-Martinez, D., Weber, F. C., Martin, S. F., et al. (2011). Mouse granzyme $\mathrm{K}$ has pro-inflammatory potential. Cell Death Differ. 18, 1112-1119. doi: 10.1038/cdd.2011.5

Kawai, T., and Akira, S. (2007). TLR signaling. Semin. Immunol. 19, 24-32. doi: 10.1016/j.smim.2006.12.004

Kawai, T., and Akira, S. (2011). Toll-like receptors and their crosstalk with other innate receptors in infection and immunity. Immunity 34, 637-650. doi: 10.1016/j.immuni.2011.05.006

Knapp, S., Wieland, C. W., Florquin, S., Pantophlet, R., Dijkshoorn, L., Tshimbalanga, N., et al. (2006). Differential roles of CD14 and toll-like receptors 4 and 2 in murine Acinetobacter pneumonia. Am. J. Respir. Crit. Care Med. 173, 122-129. doi: 10.1164/rccm.200505-730OC

Lewis, D. H., Chan, D. L., Pinheiro, D., Armitage-Chan, E., and Garden, O. A. (2012). The immunopathology of sepsis: pathogen recognition, systemic inflammation, the compensatory anti-inflammatory response, and regulatory T cells. J. Vet. Intern. Med. 26, 457-482. doi: 10.1111/j.1939-1676.2012.00905.x

Macedo, G. C., Magnani, D. M., Carvalho, N. B., Bruna-Romero, O., Gazzinelli, R. T., and Oliveira, S. C. (2008). Central role of MyD88-dependent dendritic cell maturation and proinflammatory cytokine production to control Brucella abortus infection. J. Immunol. 180, 1080-1087. doi: 10.4049/jimmunol.180.2.1080

Montaraz, J. A., and Winter, A. J. (1986). Comparison of living and nonliving vaccines for Brucella abortus in BALB/c mice. Infect. Immun. 53, 245-251.

Nymo, I. H., Arias, M. A., Pardo, J., Álvarez, M. P., Alcaraz, A., Godfroid, J., et al. (2016). Marine mammal Brucella reference strains are attenuated in a BALB/c mouse model. PLoS ONE 11:e0150432. doi: 10.1371/journal.pone.0150432

Oliveira, S. C., and Splitter, G. A. (1995). CD8+ type 1 CD44hi CD45 RBlo T lymphocytes control intracellular Brucella abortus infection as demonstrated in major histocompatibility complex class I- and class II-deficient mice. Eur. J. Immunol. 25, 2551-2557. doi: 10.1002/eji.1830250922

Olsen, S. C., and Palmer, M. V. (2014). Advancement of knowledge of Brucella over the past 50 years. Vet. Pathol. 51, 1076-1089. doi: 10.1177/0300985814540545

Pardo, J., Wallich, R., Martin, P., Urban, C., Rongvaux, A., Flavell, R. A., et al. (2008). Granzyme B-induced cell death exerted by ex vivo CTL: discriminating requirements for cell death and some of its signs. Cell Death Differ. 15, 567-579. doi: 10.1038/sj.cdd.4402289

Sabroe, I., Parker, L. C., Dower, S. K., and Whyte, M. K. (2008). The role of TLR activation in inflammation. J. Pathol. 214, 126-135. doi: 10.1002/path.2264

Salcedo, S. P., Marchesini, M. I., Lelouard, H., Fugier, E., Jolly, G., Balor, S., et al. (2008). Brucella control of dendritic cell maturation is dependent on the TIRcontaining protein Btp1. PLoS Pathog. 4:e21. doi: 10.1371/journal.ppat.0040021
Scholz, H. C., Hofer, E., Vergnaud, G., Le Fleche, P., Whatmore, A. M., Al Dahouk, S., et al. (2009). Isolation of Brucella microti from mandibular lymph nodes of red foxes, Vulpes vulpes, in lower Austria. Vector Borne Zoonotic Dis. 9, 153-156. doi: 10.1089/vbz.2008.0036

Scholz, H. C., Hubalek, Z., Nesvadbova, J., Tomaso, H., Vergnaud, G., Le Flèche, P., et al. (2008a). Isolation of Brucella microti from soil. Emerging Infect. Dis. 14, 1316-1317. doi: 10.3201/eid1408.080286

Scholz, H. C., Hubalek, Z., Sedlácek, I., Vergnaud, G., Tomaso, H., Al Dahouk, S., et al. (2008b). Brucella microti sp. nov., isolated from the common vole Microtus arvalis. Int. J. Syst. Evol. Microbiol. 58(Pt 2), 375-382. doi: 10.1099/ijs.0.65356-0

Scholz, H. C., Nöckler, K., Göibllner, C., Bahn, P., Vergnaud, G., Tomaso, H., et al. (2010). Brucella inopinata sp. nov., isolated from a breast implant infection. Int. J. Syst. Evol. Microbiol. 60(Pt 4), 801-808. doi: 10.1099/ijs.0.011148-0

Schurr, J. R., Young, E., Byrne, P., Steele, C., Shellito, J. E., and Kolls, J. K. (2005). Central role of toll-like receptor 4 signaling and host defense in experimental pneumonia caused by Gram-negative bacteria. Infect. Immun. 73, 532-545. doi: 10.1128/IAI.73.1.532-545.2005

Seleem, M. N., Boyle, S. M., and Sriranganathan, N. (2008). Brucella: a pathogen without classic virulence genes. Vet. Microbiol. 129, 1-14. doi: 10.1016/ j.vetmic.2007.11.023

Takeda, K., and Akira, S. (2005). Toll-like receptors in innate immunity. Int. Immunol. 17, 1-14. doi: 10.1093/intimm/dxh186

Takeuchi, O., and Akira, S. (2010). Pattern recognition receptors and inflammation. Cell 140, 805-820. doi: 10.1016/j.cell.2010.01.022

Takeuchi, O., Hoshino, K., and Akira, S. (2000). Cutting edge: TLR2-deficient and MyD88-deficient mice are highly susceptible to Staphylococcus aureus infection. J. Immunol. 165, 5392-5396. doi: 10.4049/jimmunol.165.10.5392

Tsujimoto, H., Ono, S., Efron, P. A., Scumpia, P. O., Moldawer, L. L., and Mochizuki, H. (2008). Role of Toll-like receptors in the development of sepsis. Shock 29, 315-321. doi: 10.1097/SHK.0b013e318157ee55

Vieira, A. L., Silva, T. M., Mol, J. P., Oliveira, S. C., Santos, R. L., and Paixão, T. A. (2013). MyD88 and TLR9 are required for early control of Brucella ovis infection in mice. Res. Vet. Sci. 94, 399-405. doi: 10.1016/j.rvsc.2012.10.028

Wang, X., Moser, C., Louboutin, J. P., Lysenko, E. S., Weiner, D. J., Weiser, J. N., et al. (2002). Toll-like receptor 4 mediates innate immune responses to Haemophilus influenzae infection in mouse lung. J. Immunol. 168, 810-815. doi: 10.4049/jimmunol.168.2.810

Weiss, D. S., Takeda, K., Akira, S., Zychlinsky, A., and Moreno, E. (2005). MyD88, but not toll-like receptors 4 and 2, is required for efficient clearance of Brucella abortus. Infect. Immun. 73, 5137-5143. doi: 10.1128/IAI.73.8.5137-5143.2005

Zal, T., Volkmann, A., and Stockinger, B. (1994). Mechanisms of tolerance induction in major histocompatibility complex class II-restricted $\mathrm{T}$ cells specific for a blood-borne self-antigen. J. Exp. Med. 180, 2089-2099. doi: $10.1084 /$ jem.180.6.2089

Zygmunt, M. S., Jacques, I., Bernardet, N., and Cloeckaert, A. (2012). Lipopolysaccharide heterogeneity in the atypical group of novel emerging Brucella species. Clin. Vaccine Immunol. 19, 1370-1373. doi: 10.1128/CVI. 00300-12

Conflict of Interest Statement: The authors declare that the research was conducted in the absence of any commercial or financial relationships that could be construed as a potential conflict of interest.

Copyright (c) 2017 Arias, Santiago, Costas-Ramon, Jaime-Sánchez, Freudenberg, Jiménez De Bagüés and Pardo. This is an open-access article distributed under the terms of the Creative Commons Attribution License (CC BY). The use, distribution or reproduction in other forums is permitted, provided the original author(s) or licensor are credited and that the original publication in this journal is cited, in accordance with accepted academic practice. No use, distribution or reproduction is permitted which does not comply with these terms. 